\title{
Skin Induration
}

National Cancer Institute

\section{Source}

National Cancer Institute. Skin Induration. NCI Thesaurus. Code C78611.

An area of hardness in the skin. Causes include inflammatory process and infiltration of the skin by malignant neoplasms. 